\title{
An operational approach to the nowcasting of an intense thunderstorm over Liguria
}

\author{
S. Gallino and B. Turato \\ ARPAL, Centro Funzionale Meteo-Idrologico di Protezione Civile della Regione Liguria (CFMI-PC), Genova, Italy
}

Received: 14 October 2005 - Revised: 10 October 2006 - Accepted: 27 October 2006 - Published: 10 January 2007

\begin{abstract}
In the period between late spring and early summer as well as in autumn, the Mediterranean is often affected by rapid development of intense convective systems. In some cases the operational NWP models are able to provide good indication of occurrence of such severe weather events (potential instability conditions) but often location and intensity of convective precipitation are poorly forecasted.

The approach of "PV-thinking" revealed itself as a good tool to identify favorable conditions for triggering such systems, partially filling this lack of information and supporting meteorologists in the very short range weather forecast. Moreover, the advanced use of data provided by SEVIRI channels onboard MSG satellite, makes possible an effective application of the PV approach, improving forecast skill also in areas where local effects are not well described by the models and/or by the data assimilation. The aim of this work is to show how the application of the MSG tools together with the PV philosophy helps in the diagnosis and nowcasting of intense thunderstorms triggered by tropopause, with particular attention to a case of intense convection over northwestern Italy during spring 2005.
\end{abstract}

\section{Introduction}

It is well known (Davis (1991) and Hoskins (1985)) that an upper PV-anomaly is associated with an abrupt folding or lowering of the dynamical tropopause. When this occurs, stratospheric air penetrates with strong winds into the troposphere resulting in high values of PV with respect to the surroundings. In the lower levels of the troposphere, strong baroclinic zones often occur which can sometimes lead to development of intense convective systems. Through this approach, cyclogenesis can be fully explained by interaction of:
- high level PV anomaly,

- jet stream (left exit/right entrance),

- surface frontal wave (baroclinic zone).

As reported by Santurette (2005) and Weldon (1991), there is a clear relationship between PV, jet stream at the dynamic tropopause and water vapor imagery from meteorological satellite. In WV imagery the jet core area can be identified as a strong humidity gradient zone and a low tropopause can be identified as a dark zone, being related with very dry stratospheric air (see Fig. 1). The synoptic motion settles around these areas of minimum geopotential height at levels around 1.5 and $2 \mathrm{PVU}$, which are consequently the most appropriate levels for the analysis of jet core.

\section{Case study: the Mesoscale Convective System of the} 23 May 2005 over Northwestern Italy

On the 23th of May 2005 a wide upper level trough aloft moved eastward from central France (see Fig. 2a), settling high instable conditions downstream western Alps where many cells of convection developed. From 08:00 UTC convection became more organized and a severe MCS grew over western Apennines (northern Tyrrhenian Sea) reaching the mature state after few hours and moving northeasterly (see Fig. 3). Heavy rainfalls were observed at ground stations with maximum values of total accumulated precipitation around $80 \mathrm{~mm} / 3 \mathrm{~h}$ inland of Genoa and Savona and rain rate between 50 and $70 \mathrm{~mm} / 1 \mathrm{~h}$ on the same areas; the radar images of derived precipitation intensity show good correlation with the observed data (see Fig. 4).

Vertical profiles in nearby stations indicate a strong dry intrusion in the upper levels, over $600 \mathrm{hPa}$ (not shown). 


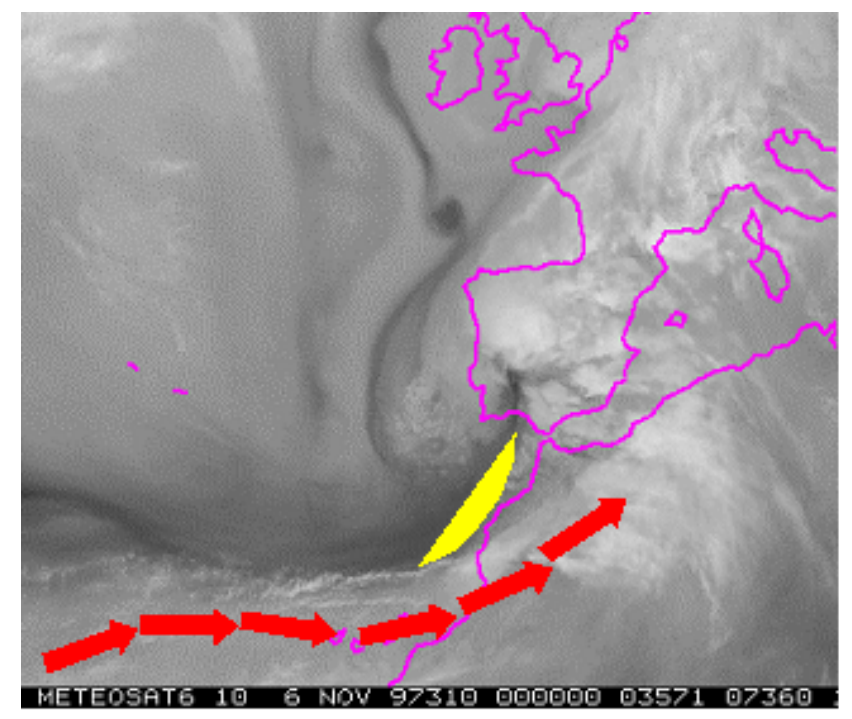

Fig. 1. Correlation between WV imagery and dynamic tropopause: dark patterns in Meteosat/MSG WV images indicate low values of water vapor in a layer between 300 and $600 \mathrm{hPa}$. The darkest areas often correspond to a dry intrusion from the tropopause. In the picture the yellow area (indicating the more dynamic part of the tropopause anomaly) is well correlated with a dark area on WV background. The jet core is indicated by red arrows.

\subsection{Traditional approach}

By means of NWP models (ECMWF, LOKAL, BOLAM) it was not possible to forecast such a system. The operational models, initialized at 12:00 UTC 22 May and 00:00 UTC 23 May, were able to describe the structure and the dynamics of the trough which was southeasterly elongated from British Isles to western Mediterranean in the morning of 23 May 2005 (Fig. 2a). A moderate geopotential fall at $500 \mathrm{hPa}$ (up to $60 \mathrm{~m}$ in $12 \mathrm{~h}$ ) was predicted by the models over a large area around central and north Italy, Switzerland and southern Germany for midday of 23 May 2005 (see Fig. 2b). Such synoptic configuration, supported by the outputs of all available models, leaded to a prediction of intense southwesterly flow at lower levels against western Apennines with diffuse and weak precipitation over the most part of Ligurian region. No signals of instability and moisture flux convergence at low levels were found also in the high resolution limited area model operational at ARPAL-CFMIPC (Bolam with $6.5 \mathrm{~km}$ horizontal grid step).

\subsection{New approach and tools}

MSG's multichannel radiometers are new powerful tools for weather analysis and nowcasting, as reported by Bader (1995). The 11 SEVIRI channels and the high resolution visible (HRV) are available with an increased time $(15 \mathrm{~min})$ and horizontal resolution (at nadir $3 \mathrm{~km}$ for SEVIRI, $1 \mathrm{~km}$ for HRV). Among the others, IR10.8 $\mu$ m provides cloud top temperature, VIS $0.6 \mu \mathrm{m}$ provides cloud optical thickness, NIR1.6 $\mu \mathrm{m}$ and IR3.9 $\mu \mathrm{m}$ are connected to particle size and
$00 Z 23$ May 2005 mslp and 500 hPa geopotential height (analysis)

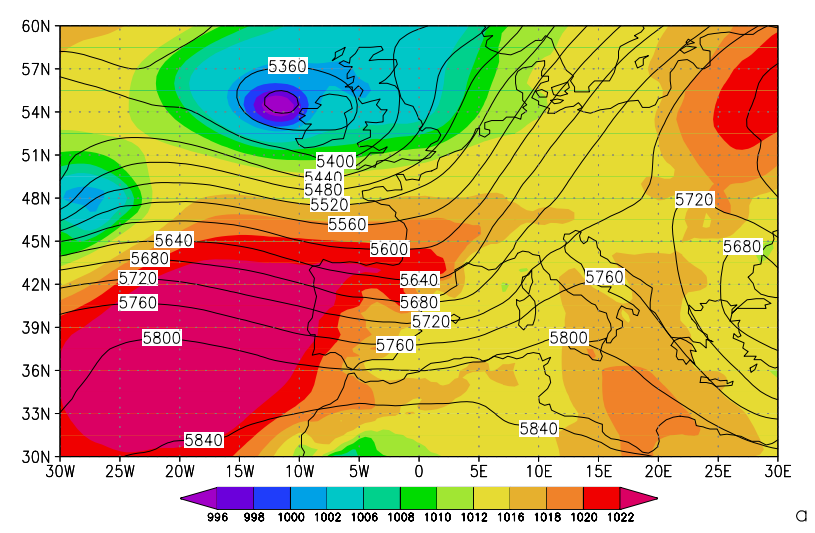

$12 \mathrm{Z} 23$ May $2005500 \mathrm{hPa}$ geopotential height tendency (for previous $12 \mathrm{hr}$ ) and geopotential height (forecast $\tau=24 \mathrm{hr}$ )

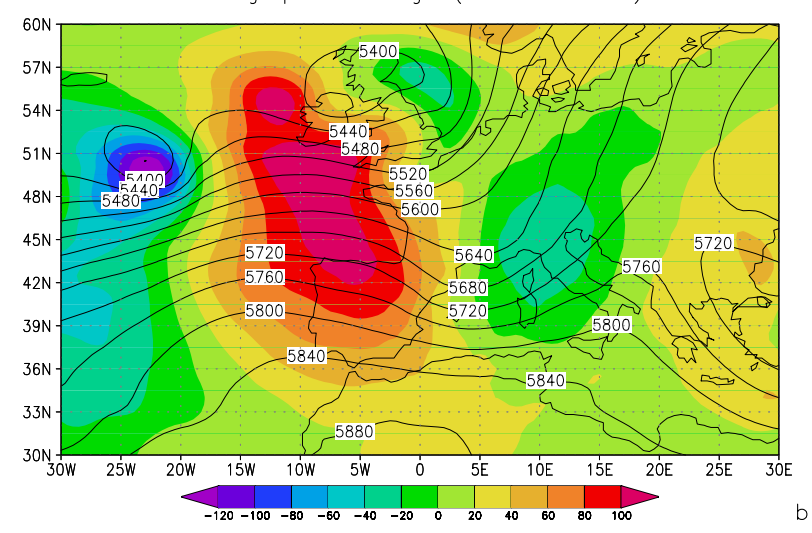

Fig. 2. (a) Mean Sea Level pressure [Pa] (shaded) and $500 \mathrm{hPa}$ geopotential height [m] (contour) at 00:00 UTC 23 May 2005. Data from ECMWF operational analysis at horizontal resolution $0.5^{\circ} \times 0.5^{\circ}$; (b) $500 \mathrm{hPa}$ geopotential tendency for previous $12 \mathrm{~h}$ (shaded) and geopotential height [m] (contour) at 12:00 UTC 23 May 2005. Data from ECMWF Operational Forecast model initialized at 12:00 UTC 22 May 2005 (forecast time $t+24$ ), horizontal resolution $0.5^{\circ} \times 0.5^{\circ}$.

phase, WV6.2 and WV7.3 show mid and upper level moisture.

Particularly, images on MSG WV6.3 $\mu \mathrm{m}$ channel (sensible to water vapor features between 500 and $150 \mathrm{hPa}$ ) show strong correlation between the tropopause anomaly (arrows in Fig. 5, 6 and 7) and MCS development. Such feature is less evident analyzing the images from traditional MET7 WV channel (see Fig. 9), sensible to lower (and moister) layers of the atmosphere (600-300 hPa).

In ECMWF forecast fields (mainly vorticity at mid-levels and geopotential height tendency) no relevant signals of the anomaly are present up to $300 \mathrm{hPa}$. Similarly, forecasts of vertical velocity, convergence-divergence, instability indices and convective precipitation given by hydrostatic and nonhydrostatic Limited Area Models of the ECMWF forecast chain (BOLAM, LAMI and LOKAL MODELL) largely underestimate nature and intensity of the event over the Liguria region (not shown). 


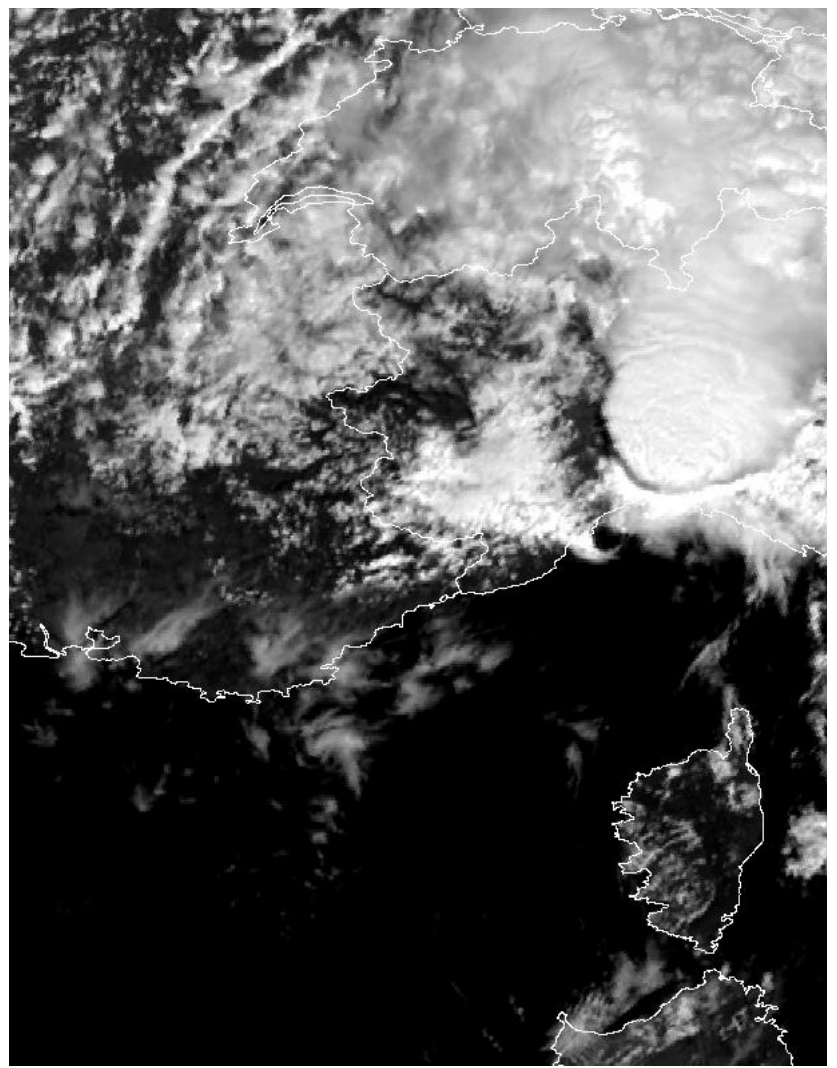

Fig. 3. HRV imagery from MSG in northwestern Italy at 11:00 UTC 23 May 2005.

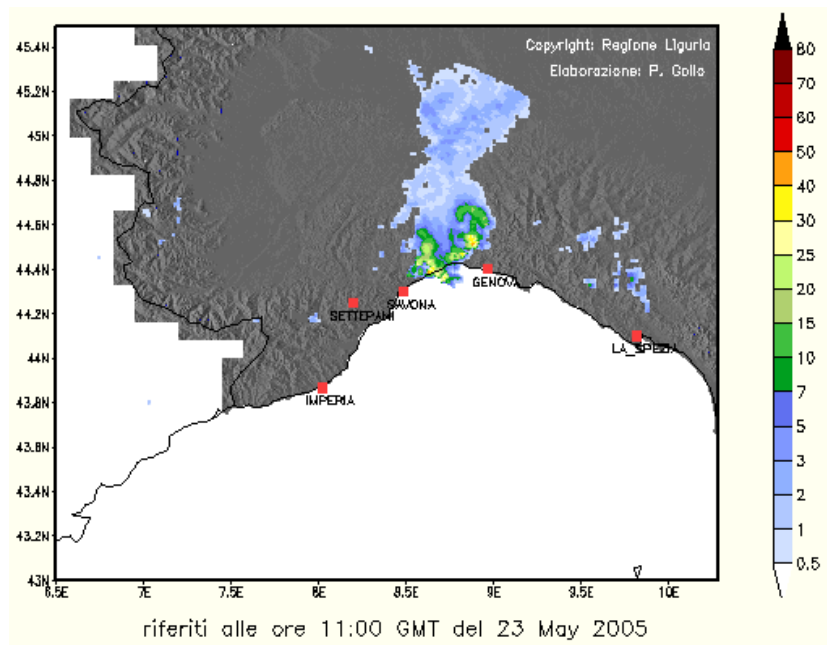

Fig. 4. Doppler Radar derived precipitation intensity $[\mathrm{mm} / \mathrm{hr}]$ at 11:00 UTC 23 May 2005.

The comparison between analysis and forecast of geopotential height and wind jet at tropopause (2PVU surface) puts in evidence that the model forecast of higher level dynamic forcings was poor: in fact, the cold region of the tropopause anomaly elongated from the Channel to the Gulf of Lion appears to be northeasterly shifted in the analysis (see Figs. 8a

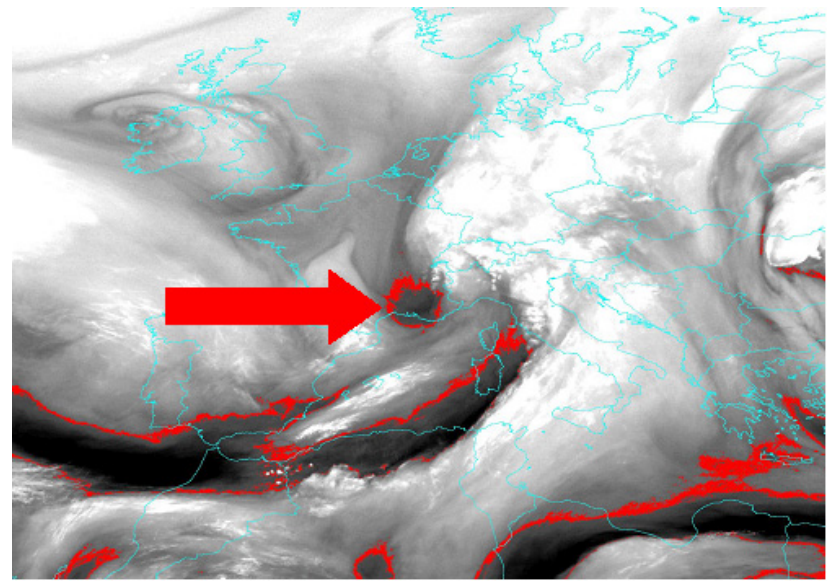

Fig. 5. MSG WV $6.3 \mu \mathrm{m}$ channel at 06:00 UTC 23 May 2005. Red contour delimits area with brightness temperature around $-35^{\circ} \mathrm{C}$, red arrow indicates tropopause anomaly.

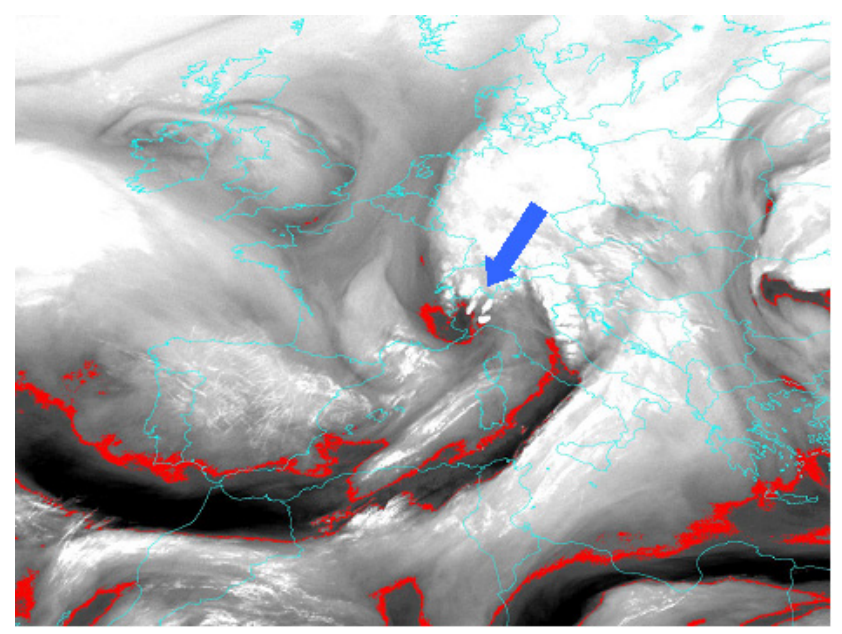

Fig. 6. MSG WV $6.3 \mu \mathrm{m}$ channel at 09:00 UTC 23 May 2005. Red contour delimits area with brightness temperature around $-35^{\circ} \mathrm{C}$, blue arrow indicates area of triggering convection.

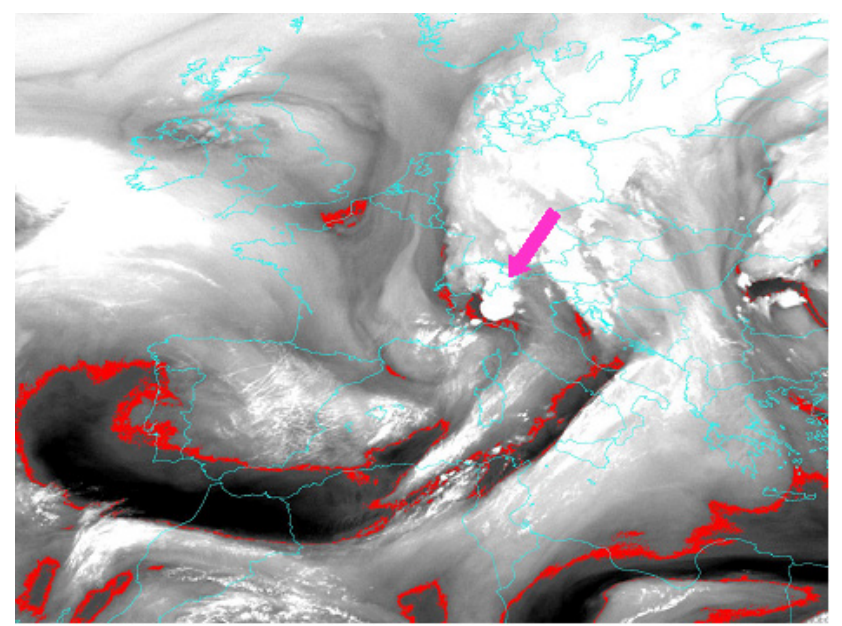

Fig. 7. MSG WV $6.3 \mu \mathrm{m}$ channel at 12:00 UTC 23 May 2005. Red contour delimits area with brightness temperature around $-35 \circ \mathrm{C}$, pink arrow indicates MCS development. 
$12 Z 23$ May 2005 tropopause geopotential height and wind jet (analysis at $2 \mathrm{PVU}$ )

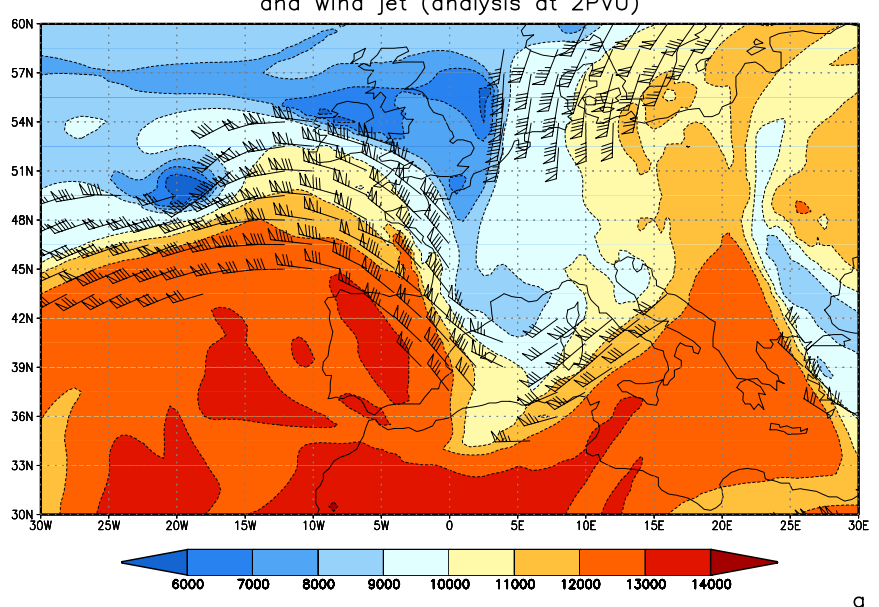

$12 Z 23$ May 2005 tropopause geopotential height and wind jet (forecast $\tau=24 \mathrm{hr}$ at $2 \mathrm{PVU}$ )

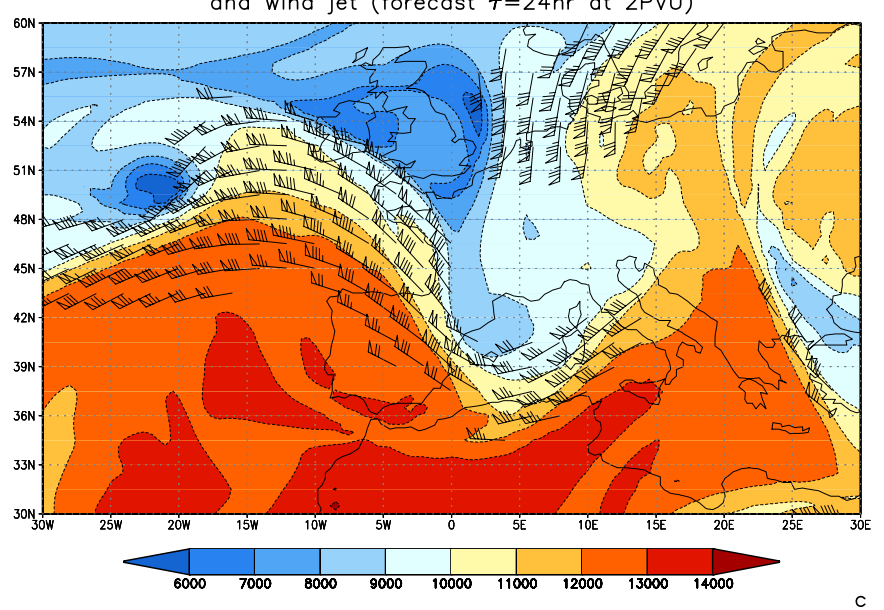

$12 Z 23$ May $2005200 \mathrm{hPa}$ Potential Vorticity (analysis)

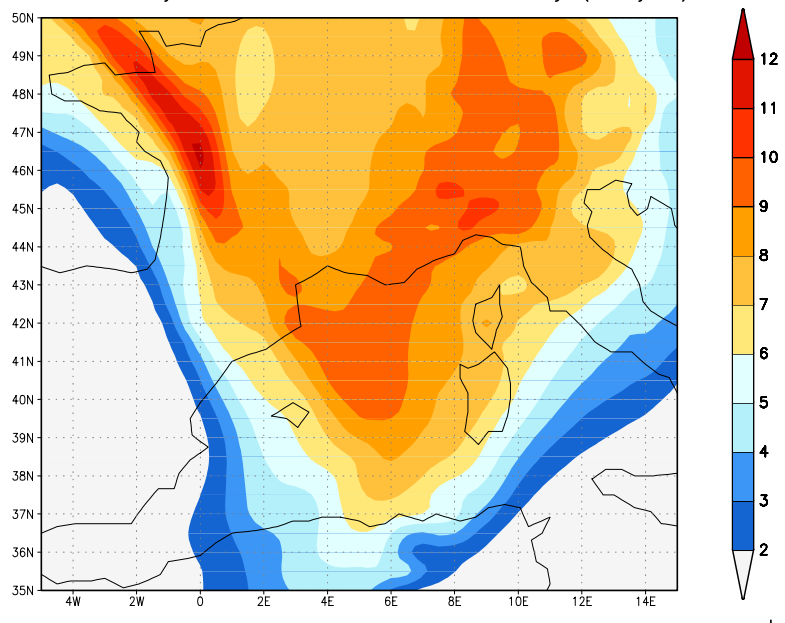

b
$12 \mathrm{Z} 23$ May $2005200 \mathrm{hPa}$ Potential Vorticity (forecast $\tau=24 \mathrm{hr}$ )

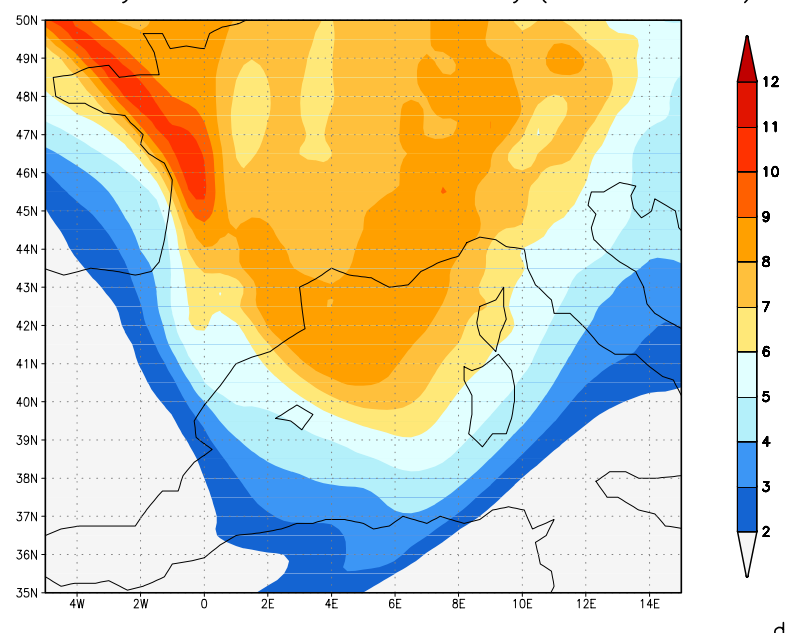

Fig. 8. 12:00 UTC 23 May 2005: (a) 2PVU Tropopause geopotential height [m] (shaded) and wind jet [knots] (barbs) (analysis); (b) $200 \mathrm{hPa}$ Potential Vorticity [PVU] (analysis) (c) Tropopause geopotential height [m] (shaded) and wind jet [knots] (barbs) (forecast); (d) $200 \mathrm{hPa}$ Potential Vorticity [PVU] (forecast). Data for figures (a) and (b) are from ECMWF operational analysis at 12:00 UTC 23 May 2005, horizontal resolution $0.5^{\circ} \times 0.5^{\circ}$ Data for figures (c) and (d) are from ECMWF Operational Forecast model initialized at 12:00 UTC 22 May 2005 (forecast time $t+24 \mathrm{hr}$ ), horizontal resolution $0.5^{\circ} \times 0.5^{\circ}$.

and $8 \mathrm{c})$. As a consequence, even the left exit region of northeasterly jet streak affecting the Mediterranean (appearing as one of the most important forcings of the MCS development, as it will be better explained in the following) seems to be slightly closer to the Genoa Gulf.

The analysis of Potential Vorticity field at $200 \mathrm{hPa}$ provides a more clear explanation of the bad model performance. In fact, in the operational analysis at $200 \mathrm{hPa}$ the large scale trough is sufficiently well represented in time and space (contour lines on Fig. 9). Moreover, small scale minima of PV downwind western Alps shows good correlation with the triggering processes of convection. Nevertheless, the forecasted fields referred to the same instant displays strong underestimation of tropopause anomaly depth and a bad description of mesoscale features (lack of the PV maximum over northwestern Italy) (compare Fig. $8 \mathrm{~b}$ and 8d.)
In order to better explain the development of the analyzed mesoscale convective system, we have to take into account the role of the upper level jet and low level convergence processes. In fact, the overlap between the mesoscale anomaly and the left exit of a northeasterly branch of the upper level jet stream during the rapid and explosive development of convection, suggests the importance of dynamical interaction between such features: the derived ascending motions were probably responsible of the deepening of a surface minimum (around $1012 \mathrm{hPa}$ ) on the western Liguria (not shown). Furthermore, the southeasterly moist flux due to the cyclonic circulation over the Gulf of Genoa interacted with the steep and complex orography of Ligurian Apennines feeding instability and providing fuel for deep convection. 
200hPa Potential Vorticity (ECMWF analysis) and WV (Meteosat7)

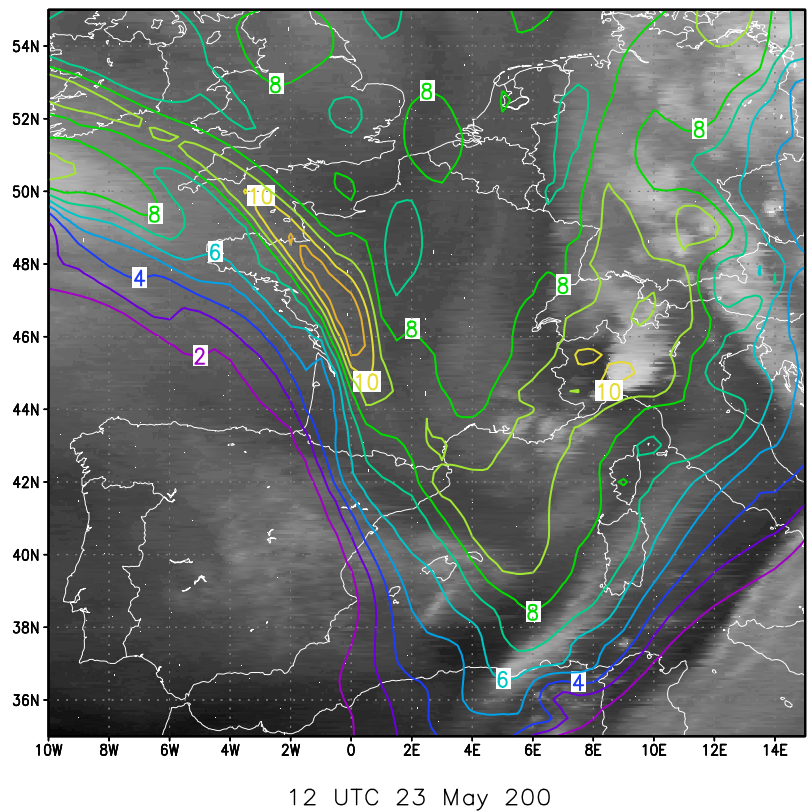

Fig. 9. 12:00 UTC 23 May 2005: METEOSAT 7 WV channel, ECMWF operational analysis of potential vorticity at $200 \mathrm{hPa}$ (PVU, superimposed contour) at $200 \mathrm{hPa}$.

Summarizing, this work puts in evidence that early detection of convection during a short-forecasting process requires:

- a careful analysis of water vapor features through different satellite channels in order to enhance small scale anomalies and to infer their height;

- verification of reliability of NWP dynamic fields (sometimes up to $200 \mathrm{hPa}$ ) through the comparison with satellite WV imagery;

- analysis of jet streak indirect circulation and its interaction with upper level dynamics;

- continuous monitoring of conditions for low level convergence of moist air, taking into account local enhancement due to orography.

\subsection{Complementary information from MSG multichannel} imagery

The works of Bellec (1992), Kidder (1995) and Rosenfeld (2004) put in evidence the importance of the RGB (Red, Green, Blue) technique, which allows to enhance physical and microphysical properties of clouds by the combined use of different radiometric channels. Usually, Red and Green are connected to microphysical properties (as optical thickness and particle size) as Blue to physical properties (reflectivity and temperature).

As it is commonly known, the color of each pixel of an image depends on a combination of different intensities of

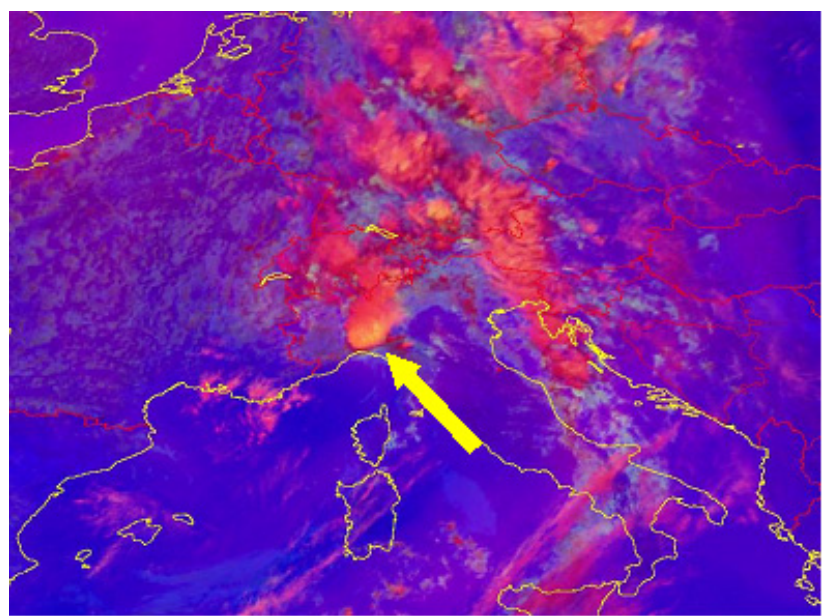

Fig. 10. RGB composite image enhancing active cells (jellow arrow) at 11:00 UTC 23 May 2005.

Red, Green and Blue. In RGB technique each of these intensities depends on the radiance/brightness temperature on certain channels or channel combinations.

In the present work we use a possible application proposed by Kerkmann (2004), which allows to distinguish young and severe storms in daytime (see section Appendix). RGB values are the results of functions of the following brightness temperature $(\mathrm{T})$ and radiance $(\mathrm{R})$ differences:

$$
\begin{aligned}
& - \text { Red }=f\left(T_{W V 6.2}-T_{W V 7.3}\right) \\
& - \text { Green }=g\left(T_{I R 3.9}-T_{I R 10.8}\right) \\
& \text { - Blue }=h\left(R_{N I R 1.6}-R_{V I S 0.6}\right)
\end{aligned}
$$

In the resulting imagery (Fig. 10), cold $\mathrm{Cb}$ tops with small thick ice particles (showing strong updrafts) appear with yellowish colors (southern part of MCS) and highlight stronger convection and severe weather; on the other hand, the presence of larger ice particles, connected to mature or dissipating phase, produces reddish colors (northern part of MCS). In this way, the forecaster is able to identify, only with satellite tools, where the precipitation could be stronger. In fact, the correlation with radar image seems to be very good (see Fig. 4).

\section{Conclusions}

In an operational context the dynamics of tropopause is an important tool to forecast conditions triggering severe convection. The conceptual model given by the PV-thinking is able to fully describe cyclogenesis. In our study we analyse a situation, typical in Mediterranean from late spring to autumn, where deep convection developed without any relevant sign in NWP. Often, as in this case, NWP analysis and forecasts miss a good description of high levels mesoscale features, which are relevant for development of explosive convection. MSG WV $6.3 \mu \mathrm{m}$ imagery partially fills this 
lack, helping forecasters to track and predict displacements of tropopause anomaly, allowing in this way to bound areas where instability will be higher (around the leading edge of the anomaly). Convection will take place if the upper dry and cold intrusion is associated with low level conditions favorable to upward motions (convergence, presence of moisture, orographic uplift). MGS, together with the PV approach, seems to be a good tool in very short range forecasting and in the nowcasting phase, especially when NPWs show a poor description of high level structure of atmosphere. Moreover multi-channels approach allows to infer microphysics properties of thunderstorms clouds.

\section{Appendix}

\section{The RGB function Severe Convection}

Among the EUMETSAT recommended schemes for RGB Image Composites using SEVERI channels (Kerkmann 2004), RGB "Severe Convection" (05-06, 04-09, 03-01) is consider to be quite useful during day-time to enhance cold $\mathrm{Cb}$ tops with small ice particles, which appear in yellowish colors (Cbs with large ice particles appear in reddish colours). In details, for each pixel the corresponding RGB values can be calculated by the following channels differences:

$$
\begin{array}{lll}
\text { Red } & = & \text { Difference WV6.2 }- \text { WV7.3 } \\
\text { Green } & =\text { Difference IR3.9* }- \text { IR10.8 } \\
\text { Blue } & =\text { Difference NIR1.6 }- \text { VIS0.6 }
\end{array}
$$

where IR3.9* is the $\mathrm{CO} 2$-corrected brightness temperature of channel 04 (see Rosenfeld 2004).

Recommended range and enhancement are reported on the following table: where gamma is the value of the exponent

\begin{tabular}{lccc}
\hline Beam & Channel diff & Range & Gamma \\
\hline Red & WV6.2 - WV7.3 & $-30 . .0$ & 1.0 \\
Green & IR3.9* - IR10.8 & $0 . .+55$ & 0.5 \\
Blue & NIR1.6 - VIS0.6 & $-70 . .+20$ & 1.0 \\
\hline
\end{tabular}

for the well known gamma correction.
Edited by: V. Kotroni and K. Lagouvardos

Reviewed by: anonymous referee

\section{References}

Bader, M. J., Forbes, G. S., Grant, J. R., Lilley, R. B. E. and Waters, A. J.: Images in weather forecasting, Cambridge Univ. Press, 1995.

Bellec, B. and Gleau, H.: The multispectral colour composite technique: an improved method to display meteorological satellite imagery, Int. J. Remote Sensing, 13, 1981-1998, 1992.

Davis, C. A. and Emanuel K. A.: Potential Vorticity Diagnostics of Cyclogenesis, Mon. Wea. Rev., 115, 1929-1953, 1991.

Hoskins, B. J., McIntyre M. E., and Robertson A. L. W.: On the use and significance of isentropic potential vorticity maps, Quart. J. R. Meteor. Soc., 111, 877-946, 1985.

Kerkmann, J., Lutz, H. J., Kønig, M., Prieto, J., Pylkko, P., Roesli, H. P., Rosenfeld, D., Schmetz, J., and Zwatz-Meise, V.: MSG Interpretation Guide, Version 1.0, edited by: Zwatz-Meise, V. and Kerkmann, J., available at: http://oiswww.eumetsat.org/ WEBOPS/msg_interpretation/, 2004.

Kidder, S. Q. and Vonder Haar, T. H.: Satellite Meteorology, Academic Press, 1995.

Rosenfeld, D.: Understanding clouds and precipitation system with MSG, Proceedings of 2004 Eumetsat Conference, EUM P 41, ISBN 92-9110-066-8, 2004.

Santurette, P. and Georgiev, C. G.: Weather analysis and forecasting: applying satellite Water Vapor imagery and Potential Vorticity analysis, Burlington, MA, Elsevier/Academic Press, 2005.

Weldon, R. B. and Holmes, S. J.: Water Vapor Imagery. Interpretation and applications to weather analysis and forecasting. NOAA Technical Report NESDIS 57, 1991. 